\title{
Laparoscopic radical gastrectomy versus traditional open surgery in elderly patients with gastric cancer: Benefits and complications
}

\author{
HONGTAO LI ${ }^{1 *}$, XIAOPENG HAN ${ }^{1 *}$, LIN SU ${ }^{1}$, WANKUN ZHU ${ }^{1}$, WEI XU ${ }^{1}$,

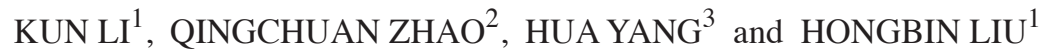 \\ ${ }^{1}$ Department of General Surgery, General Hospital of Lanzhou Military Region, Lanzhou, Gansu 730050; \\ ${ }^{2}$ Xijing Hospital of Digestive Disease, The Fourth Military Medical University, Xi'an, Shaanxi 710032; \\ ${ }^{3}$ Xinqiao Hospital, The Third Military Medical University, Chongqing 400037, P.R. China
}

Received February 12, 2014; Accepted April 11, 2014

DOI: $10.3892 / \mathrm{mco} .2014 .283$

\begin{abstract}
This study was conducted to compare the therapeutic effect and complications of laparoscopic radical gastrectomy (LRG) with those of traditional open surgery in elderly patients with gastric cancer (GC). We conducted a retrospective comparison of therapeutic efficacy and complications between elderly patients with GC (defined as those aged $\geq 70$ years) who received laparoscopic gastrectomy and those who underwent gastrectomy by open surgery. A total of 108 patients who either underwent laparoscopic surgery $(n=54)$ or traditional open surgery $(n=54)$ at the General Hospital of Lanzhou Military Region between June, 2008 and March, 2009 were analyzed. Compared to traditional open surgery, LRG exhibited several advantages, such as being less invasive, with less intraoperative blood loss, shorter bedbound time, less intubation time, low frequency of fever, less time to normal diet, shorter hospital stay and a low overall incidence of complications. No significant difference was observed between laparoscopic and open surgery in terms of operative time and number of lymph nodes dissected. The 3-year cancer recurrence and mortality rates were similar in the two groups. In conclusion, LRG is a safe and effective procedure for the management of GC in elderly patients and was found to be superior to traditional open surgery regarding the short-term curative effect. Therefore, LRG represents a feasible and safe surgical approach for elderly patients with GC.
\end{abstract}

Correspondence to: Dr Hongbin Liu, Department of General Surgery, General Hospital of Lanzhou Military Region, 333 Binhe South Road, Lanzhou, Gansu 730050, P.R. China

E-mail: liuhongbin999@163.com

*Contributed equally

Key words: gastric cancer, laparoscopic radical gastrectomy, traditional open surgery, curative effect, prognosis

\section{Introduction}

Gastric cancer (GC) is one of the most common cancers worldwide, accounting for 700,000 deaths annually (1). The incidence of GC among elderly individuals has gradually increased due to the improvement in living conditions, extended life span and aging of the population. As recently reported, the majority of the new cases of GC occurred in elderly individuals (2).

The symptoms of GC in elderly patients are generally atypical and are often masked by concurrent diseases. Elderly patients do not usually tolerate surgery as well and often suffer from multiple postoperative complications, hence the poor prognosis (3). Therefore, gastrectomy may be a challenging surgical procedure for elderly patients with GC.

Laparoscopic radical gastrectomy (LRG) was first introduced in 1994 and has since been considered to be a viable surgical option for GC (4). This procedure is associated with minimal postoperative pain, low degree of trauma, rapid recovery of gastrointestinal function and reduced hospital stay. In addition, this procedure has only a minimal impact on immune function and is thus associated with better survival and improved quality of life. Therefore, LRG has become one of the optimal surgical approaches for the treatment of GC.

Clinical trials in younger patients indicated that LRG is associated with similar or fewer intraoperative and postoperative complications compared to open surgery (5-7). However, the safety profile, feasibility and curative effects of LRG have not been clearly determined in elderly patients. In the present retrospective study, we compared the benefits, complications and patient survival profile between elderly patients who underwent a laparoscopic procedure and those who underwent open surgery in a single centre in China.

\section{Materials and methods}

Patients. This study included 108 patients aged $>70$ years who underwent radical gastrectomy at the General Hospital of Lanzhou Military Region between June, 2008 and March, 2009. All the patients had an American Society of Anesthesiologists score $\geq I V(8)$ and were considered to be suitable for surgery. In all the cases, surgery was performed by the same surgical team and the diagnosis was confirmed by postoperative pathology. 
Table I. Patient characteristics.

\begin{tabular}{|c|c|c|c|c|}
\hline Parameters & LRG, $\mathrm{n}=54(\%)$ & Open surgery, $\mathrm{n}=54(\%)$ & $\chi^{2}$ & P-value \\
\hline Age, years $($ mean $\pm S D)$ & $78.6 \pm 6.5$ & $76.5 \pm 7.2$ & & 0.135 \\
\hline Male/female & $36 / 18$ & $30 / 24$ & 1.40 & 0.236 \\
\hline Pathological type & & & 0.89 & 0.828 \\
\hline Well differentiated adenocarcinoma & $13(24.1)$ & $17(31.5)$ & & \\
\hline Moderately differentiated adenocarcinoma & $6(11.1)$ & $5(9.3)$ & & \\
\hline Poorly differentiated adenocarcinoma & $32(59.3)$ & $30(55.5)$ & & \\
\hline Signet ring cell carcinoma & $3(5.5)$ & $2(3.7)$ & & \\
\hline Degree of invasion & & & 0.38 & 0.83 \\
\hline $\mathrm{T} 1$ & $5(9.3)$ & $4(7.4)$ & & \\
\hline $\mathrm{T} 2$ & $23(42.6)$ & $26(48.1)$ & & \\
\hline $\mathrm{T} 3$ & $26(48.1)$ & $24(44.5)$ & & \\
\hline Lymph node metastasis & & & 0.68 & 0.88 \\
\hline N0 & $3(5.5)$ & $5(9.3)$ & & \\
\hline N1 & $23(42.6)$ & $21(38.9)$ & & \\
\hline N2 & $21(38.9)$ & $20(37.0)$ & & \\
\hline N3 & $7(13.0)$ & $8(14.8)$ & & \\
\hline Clinical staging & & & 0.34 & 0.56 \\
\hline $\mathrm{I} / \mathrm{II}$ & $24(44.4)$ & $21(38.9)$ & & \\
\hline III/IV & $30(55.6)$ & $33(61.1)$ & & \\
\hline Preoperative comorbidities/conditions & & & 1.21 & 0.94 \\
\hline Cardiovascular disorders & $33(61.1)$ & $34(63.0)$ & & \\
\hline Diabetes mellitus & $12(22.2)$ & $16(29.6)$ & & \\
\hline Respiratory diseases & $23(42.6)$ & $19(35.2)$ & & \\
\hline Hypoproteinemia & $13(24.1)$ & $13(24.1)$ & & \\
\hline Cerebral infarction & $6(11.1)$ & $5(9.3)$ & & \\
\hline Electrolyte disorders & $11(20.4)$ & $13(24.1)$ & & \\
\hline Total & $46(85.2)$ & $44(81.5)$ & 0.27 & 0.61 \\
\hline
\end{tabular}

LRG, laparoscopic radical gastrectomy; SD, standard deviation.

No patients exhibited evidence of remote metastasis on gastroscopy, computed tomography scan or magnetic resonance imaging examination. No patients had received any immunotherapy or had undergone preoperative chemo- and/or radiotherapy within 6 months of surgery. Furthermore, no patients experienced a switch from laparoscopic surgery to an open approach intraoperatively.

Clinical manifestations. All the patients presented with various degrees of abdominal discomfort. The major clinical manifestations included upper quadrant abdominal pain or bloating ( $n=86,79.6 \%)$, loss of appetite $(n=64,59.3 \%)$, fatigue or weight loss $(n=82,75.9 \%)$, melena $(n=34,34.5 \%)$, nausea and vomiting $(\mathrm{n}=34,34.5 \%)$ and a choking sensation during eating $(n=23,32.5 \%)$. The interval between the onset of symptoms and hospital admission was $<1$ month in 37 patients $(34.4 \%)$, 1-3 months in 45 patients $(41.7 \%)$, 4-6 months in 18 patients (16.7\%) and $>6$ months in 8 patients $(7.4 \%)$.

The major comorbidities included cardiovascular or respiratory diseases, diabetes mellitus, hypoproteinemia, central nervous system disorders and electrolyte imbalance.
Surgical approach. The patients were randomly divided into a laparoscopic operation group $(n=54)$ and a traditional open surgery group $(n=54)$. All the patients underwent standard lymph node dissection, according to the GC D2 radical procedure (9). In the laparoscopic group, 42 patients underwent radical surgery and 12 received palliative surgery. The type of procedures included total $(n=31)$, proximal $(n=14)$ and distal gastrectomy $(n=9)$. In the open surgery group, 44 patients received radical surgery and 10 received palliative surgery. The type of procedures in this group also included total $(n=33)$, proximal $(n=11)$ and distal gastrectomy $(n=10)$.

Postoperatively, all the patients received 6 cycles of standard FOLFOX4 chemotherapy.

Statistical analysis. The statistical analysis was performed using SPSS version 18.0 software (SPSS, Inc., Chicago, IL, USA). Continuous data were analyzed using t-tests and are presented as means \pm standard deviation. Categorical data were analyzed using the Chi-square test. The log-rank test was used to evaluate survival data. $\mathrm{P}<0.05$ was considered to indicate a statistically significant difference. 
Table II. Intraoperative and postoperative data.

\begin{tabular}{|c|c|c|c|c|}
\hline Parameters & $\mathrm{LRG}, \mathrm{n}=54($ mean $\pm \mathrm{SD})$ & Open surgery, $n=54$ & $t$-value & P-value \\
\hline \multicolumn{5}{|l|}{ Intraoperative } \\
\hline Operation time (min) & $179.4 \pm 22.5$ & $173.0 \pm 28.8$ & 1.288 & 0.201 \\
\hline Blood loss (ml) & $103.0 \pm 34.4$ & $140.6 \pm 44.4$ & -4.917 & 0.000 \\
\hline Lymph nodes resected (no.) & $27.8 \pm 3.9$ & $26.7 \pm 4.6$ & 1.391 & 0.167 \\
\hline Incision length $(\mathrm{cm})$ & $5.18 \pm 0.7$ & $17.8 \pm 1.0$ & -74.258 & 0.000 \\
\hline \multicolumn{5}{|l|}{ Postoperative } \\
\hline Bedbound time (days) & $1.0 \pm 0.3$ & $3.2 \pm 0.5$ & -29.766 & 0.000 \\
\hline Intubation time (days) & $0.8 \pm 0.2$ & $1.6 \pm 0.7$ & -7.921 & 0.000 \\
\hline Fever (days) & $2.2 \pm 0.8$ & $3.2 \pm 0.8$ & -8.593 & 0.000 \\
\hline Time to normal diet (days) & $3.0 \pm 0.4$ & $3.8 \pm 0.8$ & -8.942 & 0.000 \\
\hline Time to bowel open (days) & $3.2 \pm 0.8$ & $3.6 \pm 0.7$ & -2.473 & 0.015 \\
\hline Hospital stay (days) & $7.0 \pm 1.3$ & $9.4 \pm 1.5$ & -8.987 & 0.000 \\
\hline
\end{tabular}

LRG, laparoscopic radical gastrectomy; SD, standard deviation.

\section{Results}

Patient characteristics. The study population included 66 men and 42 women, aged 70-89 years (mean age, 77.6 years). No significant difference between the laparoscopic and open surgical groups was observed in terms of age, gender distribution, pathological type of cancer, TMN status, clinical stage and preoperative comorbidities (Table I).

Intraoperative and postoperative outcomes. Except for the operative time required and the number of lymph nodes dissected, which did not differ significantly between the two types of surgical procedures (P-values of 0.201 and 0.167 , respectively), all other major intra- and postoperative indices were significantly superior with LRG compared to those with open surgery. For example, compared to patients who underwent open surgery, patients who received laparoscopic surgery exhibited a significantly reduced intraoperative

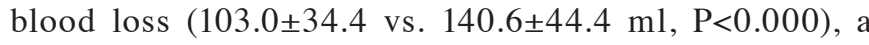
significantly smaller incision size $(5.18 \pm 0.7$ vs. $17.8 \pm 1.0 \mathrm{~cm}$, $\mathrm{P}<0.000)$ and a significantly shorter bedbound time $(1.0 \pm 0.3$ vs. $3.2 \pm 0.5$ days, $\mathrm{P}=0.000)$. Further details are shown in Table II.

Postoperative complications. Postoperative complications were reported in 8 patients $(14.8 \%)$ who underwent laparoscopic surgery and in $16(29.6 \%)$ who received open surgery $(\mathrm{P}=0.04)$. One patient who underwent open surgery succumbed to a lung and abdominal infection and subsequent multiple organ failure. There were no reported deaths in the laparoscopic surgery group. Further details on postoperative complications are listed in Table III.

Follow-up. The patients were followed up for 3 years. The 6-month, 1- and 3-year survival rates were 92.6, 85.2 and $55.6 \%$, respectively, among patients who underwent laparoscopic surgery and $88.9,81.5$ and $57.4 \%$ respectively, among those who underwent open surgery (Table IV). The median
Table III. Postoperative complications.

\begin{tabular}{|c|c|c|c|}
\hline Complications $^{\mathrm{a}}$ & $\begin{array}{c}\mathrm{LRG} \\
\mathrm{n}=54(\%)\end{array}$ & $\begin{array}{l}\text { Open surgery, } \\
n=54(\%)\end{array}$ & P-value \\
\hline $\begin{array}{l}\text { Gastrointestinal } \\
\text { hypomotility }\end{array}$ & $2(3.7)$ & $3(5.6)$ & \\
\hline Anastomotic bleeding & 0 & 0 & \\
\hline Anastomotic leakage & $3(5.6)$ & $5(9.3)$ & \\
\hline Abdominal infection & $3(5.6)$ & $6(11.1)$ & \\
\hline $\begin{array}{l}\text { Poor healing } \\
\text { of incision }\end{array}$ & $2(3.7)$ & $9(16.7)$ & \\
\hline Urinary tract infection & $1(1.9)$ & $5(9.3)$ & \\
\hline Pulmonary infection & $3(5.6)$ & $5(9.3)$ & \\
\hline Respiratory failure & 0 & $1(1.9)$ & \\
\hline $\begin{array}{l}\text { Liver/kidney } \\
\text { dysfunction }\end{array}$ & $2(3.7)$ & $1(1.9)$ & \\
\hline Heart failure & $1(1.9)$ & $1(1.9)$ & \\
\hline $\begin{array}{l}\text { Deep venous } \\
\text { thrombosis }\end{array}$ & 0 & 0 & \\
\hline Intestinal obstruction & $1(1.9)$ & $4(7.4)$ & \\
\hline Death & 0 & $1(1.9)$ & \\
\hline Total & $8(14.8)$ & $16(29.6)$ & 0.040 \\
\hline
\end{tabular}

${ }^{\mathrm{a}} \mathrm{A}$ total of 11 patients presented with $\geq 2$ complications. LRG, laparoscopic radical gastrectomy.

survival was 26.8 months (95\% confidence interval: $23.6-30.0)$ in both groups.

The Kaplan-Meier survival curves for the two groups are shown in Fig. 1. By the log-rank test, there was no significant difference in survival between the two surgical techniques $\left(\chi^{2}=0.079 ; \mathrm{P}=0.779\right)$.

All the patients who underwent palliative surgery succumbed to disease progression during the 3-year follow-up period. The causes of death in the laparoscopic surgery group 
Table IV. Number of patients who survived during the follow-up period.

\begin{tabular}{lcccc}
\hline $\begin{array}{l}\text { Time } \\
\text { (years) }\end{array}$ & $\begin{array}{c}\text { LRG, } \\
\mathrm{n}=54(\%)\end{array}$ & $\begin{array}{c}\text { Open surgery, } \\
\mathrm{n}=54(\%)\end{array}$ & $\chi^{2}$ & P-value \\
\hline $1 / 2$ & $50(92.6)$ & $48(88.9)$ & 0.441 & 0.507 \\
1 & $46(85.2)$ & $44(81.5)$ & 0.267 & 0.606 \\
3 & $30(55.6)$ & $31(57.4)$ & 0.038 & 0.846 \\
\hline
\end{tabular}

LRG, laparoscopic radical gastrectomy.

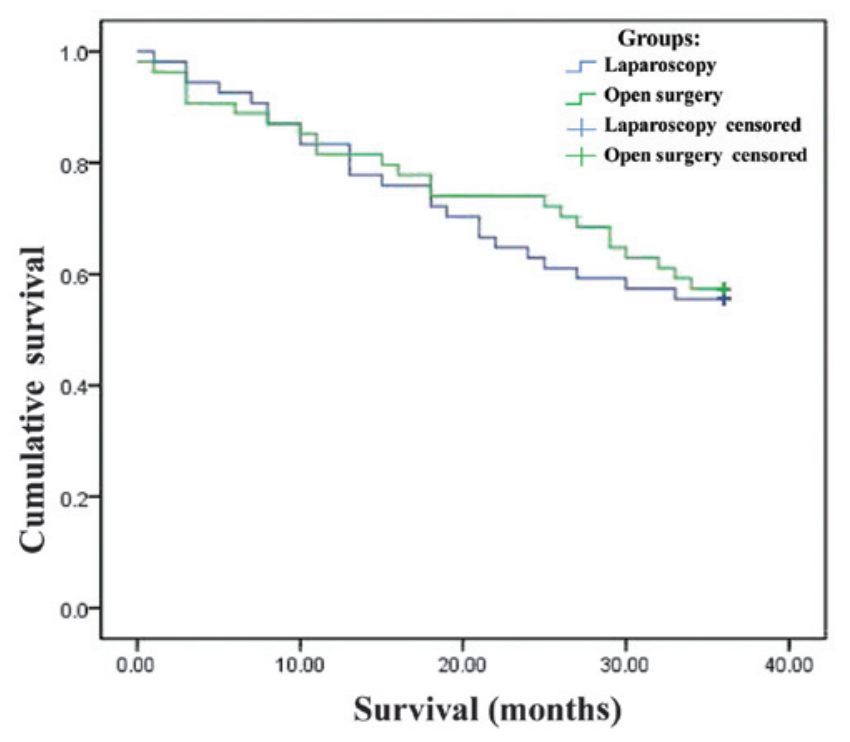

Figure 1. Survival functions.

included cardiovascular accidents $(\mathrm{n}=10)$, extensive abdominal and peritoneal metastasis $(n=8)$ and liver metastasis $(n=3)$. Of the patients who underwent palliative treatment through open surgery, 7 died due to cardiovascular accidents, 9 due to extensive abdominal and peritoneal metastasis and 2 due to liver metastasis (data not shown).

\section{Discussion}

The symptoms of GC are usually not overt in elderly patients, partly due to an underlying reduction in physiological functionality and partly because the symptoms are often attributed to other comorbidities. Elderly patients with early-stage GC are often either asymptomatic or present with non-specific symptoms, such as dull pain in the upper quadrant, abdominal discomfort, loss of appetite and weight loss (10). Therefore, at the time of diagnosis, the disease has often reached an advanced stage and is difficult to treat. Consequently, in all suspected GC cases, endoscopy and upper gastrointestinal barium meal examination are required for early diagnosis.

Surgery remains the major therapeutic approach for GC. However, elderly patients may not be able to tolerate surgery and are more susceptible to postoperative complications and increased mortality risk as a result of multiple concurrent diseases and declining organ function.
A number of elderly patients exhibit a poor compensatory ability due to a weakened immune system, which may be exacerbated by long-term nutritional insufficiency and digestive tract hemorrhage. The presence of multiple coexisting diseases highlights the significance of a thorough preoperative investigation of heart, lung, liver and kidney function, as well as determination of the coagulation profile and blood glucose levels. Malnutrition and anemia should be corrected prior to surgery and steps should be taken to improve the respiratory function, such as quitting smoking and physiotherapy to improve effective coughing and expectoration. Palliative surgery should be considered for patients with multiple, severe concurrent diseases.

The first laparoscopic partial gastrectomy for early-stage GC was undertaken in 1994 in an attempt to reduce the iatrogenic trauma associated with gastrectomy (11). This was followed 5 years later by LRG for advanced GC, including D2 lymph node dissection (12). A retrospective study of 1,294 patients undergoing gastrectomy at 16 medical centers in Japan reported that laparoscopic and open surgery were of equivalent therapeutic value, feasibility and safety (13). Based on those findings, laparoscopic surgery has been accepted as a novel minimally invasive surgical option for GC patients. However, elderly patients are generally less tolerant to the pneumoperitoneum that forms an essential part of the laparoscopic procedure. The relatively long operative time required for LRG has also limited its application in elderly patients.

Our previous experience with laparoscopic surgery suggests that this type of procedure is able to preserve the integrity of the dissected lymph nodes and lymph ducts, provided that any associated lymphatic and connective tissues are removed en bloc. Laparoscopy facilitates this part of the operative procedure, as the surgical view is amplified, enabling complete removal of all malignant tissue and reducing the risk of recurrence.

Our present study revealed that laparoscopic surgery is advantageous over open surgery in a number of important postoperative endpoints (Table III), which is is partially in line with previously reported data (14). Compared to open surgery, laparoscopic surgery was found to be associated with less intraoperative blood loss, rapid intestinal recovery (i.e., shorter time to bowel function following surgery), less bedbound time, less intubation time and less overall hospital stay. Unlike previous reports suggesting that laparoscopy requires a significantly longer time compared to open gastrectomy in elderly patients, our data demonstrated that the mean operative time was longer by only 6.4 minutes with laparoscopic surgery compared to that with open surgery; this difference was marginal and of no statistic significance. As the laparoscopic procedure is more complicated compared to open surgery, a longer learning curve is required. However, to certain extent, the duration of surgery depends on the experience of the surgeon and the complexity of each case.

In line with previous studies, our analysis indicated that laparoscopic surgery is associated with fewer postoperative complications compared to open surgery. A recent study in GC patients reported a postoperative complication rate of $25.3 \%$ with laparoscopic surgery $(n=629)$ and $40.1 \%$ with open surgery $(n=1,002)$. In our study, the overall postoperative complication rate was $14.8 \%$ with laparoscopic surgery $(n=8)$ and $29.6 \%$ with open surgery $(n=16)$. When used for radical 
and palliative gastrectomy with lymph node dissection, the two procedures had a similar impact on long-term survival, which is consistent with previous studies $(15,16)$.

In summary, LRG appears to be superior to open surgery in improving patient survival and quality of life when combined with appropriate perioperative care in elderly patients with GC.

\section{References}

1. Jemal A, Bray F, Center MM, et al: Global cancer statistics. CA Cancer J Clin 61: 69-90, 2011.

2. Bai Y and Li ZS: Endoscopic, clinicopathological features and prognosis of very young patients with gastric cancer. J Gastroenterol Hepatol 26: 1626-1629, 2011.

3. Saif MW, Makrilia N, Zalonis A, et al: Gastric cancer in the elderly: an overview. Eur J Surg Oncol 36: 709-717, 2010.

4. Kitano S, Iso Y, Moriyama M, et al: Laparoscopy-assisted Billroth I gastrectomy. Surg Laparosc Endosc 4: 146-148, 1994.

5. Pugliese R, Maggioni D, Sansonna F, et al: Outcomes and survival after laparoscopic gastrectomy for adenocarcinoma. Analysis on 65 patients operated on by conventional or robot-assisted minimal access procedures. Eur J Surg Oncol 35: 281-288, 2009

6. Hwang SI, Kim HO, Yoo CH, et al: Laparoscopic-assisted distal gastrectomy versus open distal gastrectomy for advanced gastric cancer. Surg Endosc 23: 1252-1258, 2009.

7. Francescutti V, Choy I, Biertho L, et al: Gastrectomy and esophagogastrectomy for proximal and distal gastric lesions: a comparison of open and laparoscopic procedures. Surg Innov 16: 134-139, 2009.
8. Munish M, Sharma V, Yarussi KM, et al: The use of practice guidelines by the American Society of Anesthesiologists for the identification of surgical patients at high risk of sleep apnea. Chron Respir Dis 9: 221-230, 2012.

9. Uyama I, Sakurai Y, Komori Y, et al: The advances of laparoscopic treatment for gastric cancer. Cancer \& Chemotherapy 34: 21-24, 2007 (In Japanese).

10. Ramesh HS, Pope D, Gennari R, et al: Optimising surgical management of elderly cancer patients. World J Surg Oncol 3: $17,2005$.

11. Ohgami M, Otani Y, Kumai K, et al: Laparoscopic wedge resection of the stomach for early gastric cancer using a lesion-lifting-method: curative and minimally invasive treatment. Zentralbl Chir 123: 465-468, 1998 (In German).

12. Uyama I, Sugioka A, Fujita J, et al: Purely laparoscopic pylorus-preserving gastrectomy with extraperigastric lymphadenectomy for early gastric cancer: a case and technical report. Surg Laparosc Endosc Percutan Tech 9: 418-422, 1999.

13. Kitano S, Shiraishi N, Uyama I, et al: A multicenter study on oncologic outcome of laparoscopic gastrectomy for early cancer in Japan. Ann Surg 245: 68-72, 2007.

14. Kunisaki C, Makino H, Takagawa R, et al: Efficacy of laparoscopy-assisted distal gastrectomy for gastric cancer in the elderly. Surg Endosc 23: 377-383, 2009.

15. Ibanez Aguirre FJ, Azagra JS, Erro Azcarate ML, et al: Laparoscopic gastrectomy for gastric adenocarcinoma. Long-term results. Rev Esp Enferm Dig 98: 491-500, 2006 (In English, Spanish)

16. Azagra JS, Ibanez-Aguirre JF, Goergen M, et al: Long-term results of laparoscopic extended surgery in advanced gastric cancer: a series of 101 patients. Hepatogastroenterology 53: 304-308, 2006. 